\title{
Serotonin as a Marker to the Response of Patients with Advanced Stages of Cancer during Treatment with Chemotherapy and Radiotherapy
}

Rasha Hasan Jasim* and Noor Sabah Matlab

Department of Chemistry, Faculty of Education for Girls, University of Kufa, Iraq

\begin{abstract}
Serotonin is synthesized by conversion L-tryptophan into 5-hydroxytryptamine in the body by using two catalyze factors are tryptophan hydroxylase and 5-hydroxytryptophan decarboxylase, it exhibits a growth stimulatory effect on several types of carcinoma, carcinoid and other tumor cells. In contrast, few data are available on serotonin involvement in cancer cell migration and metastatic processes. Serum serotonin level was found to be suitable for prognosis evaluation of urothelial carcinoma in the urinary bladder, adenocarcinoma of the prostate and renal cell carcinoma. Subjects: 201 patients with malignant tumors, 74 patients with different benign tumors and 83 healthy individuals were enrolled in the present study. Results: Outresults show a significant increase $(p=0.011$ and 0.043$)$ of serum serotonin levels in malignant tumors group when compared with those of benign tumors (as a pathological controls) group, and healthy individuals groups; respectively. No such results were shown when the two control (benign tumors and healthy individuals) groups were compared together. Conclusion: Increase of serotonin could be related to activation of the serotonergic receptors sensitivity.
\end{abstract}

Keywords: Serotonin; Cancer; Chemotherapy; Radiotherapy

\section{Introduction}

Malignant tumor (cancerous tumors) has the capability to invade neighboring tissue and moves to other sites in the body [1,2]. When it gets a change in the gene to normal cells due to mutations healthy cells become cancerous because of this situation produces a change in the construct and sequence of nitrogenous bases of DNA [1]. The DNA damaged is not repaired, the new cells don't have the same damaged DNA and do not people can inherit damaged DNA. As a result, the cell becomes a source of harm to the body [3-5]. Cancer takes a relative long time to develop because multiple genetic alterations are required to transform normal cells into malignant cells. A single change in one oncogene or tumor suppressor gene in an individual cell is not adequate for transformation, so that, cells accumulate multiple mutations through clonal expansion [6-9].

In mammals serotonin produced principally by enterochromaffin cells, it is found within the gut and stored within blood platelets. In the brain, serotonin is produced within axon terminals, where it is released in response to an action potential and then diffuses across the synapse to activate postsynaptic receptors. It specialized groups of cell bodies known as the raphe nuclei, located in the brainstem reticular formation [10]. Serotonin has an effect on the number of physiologic and behavioral function, It plays a number of very important roles in normal brain function, which include modulation of mood states, memory, emotion, anxiety, endocrine effects appetite, hunger, aggression, cognition, gastrointestinal function, emesis, endocrine function, motor function, perception, neurotrophism, sensory function, sex, sleep and vascular function, and many others $[11,12]$. Serotonin exhibits a growth stimulatory effect on several types of carcinoma, carcinoid and other tumor cells. In contrast few data are available on serotonin involvement in cancer cell migration and metastatic processes. Serum serotonin level was found to be suitable for prognosis evaluation of urothelial carcinoma in the urinary bladder, adenocarcinoma of the prostate and renal cell carcinoma. It actually used in oncology as tumor marker of gastrointestinal carcinoid, hepatic and ovarian carcinoid [13], in addition to, serotonin can be used as specific tumor marker for gastrointestinal tumors of the pancreatic islet cells and intestinal tract $[12,14]$. Serotonin is synthesized by conversion L-tryptophan into 5 -hydroxytryptamine in the body by using two catalyze factors are tryptophan hydroxylase and 5-hydroxytryptophan decarboxylase $[11,15]$. In mammals, serotonin is biosynthetically derived by two enzymatic steps: (1) ring hydroxylation of the essential amino acid tryptophan by tryptophan hydroxylase, the rate-limiting step, and (2) side chain decarboxylation by aromatic amino acid decarboxylase [10-13].

This process occurs in number of systems body such as immune system cells and gastrointestinal tract (GIT), central and peripheral nervous system [12,16]. GI contains $90 \%$ of serotonin and it is synthesized basically in enterochromaffin cells and in enteric neurons of submucous and myenteric plexus layer [12]. When the serotonin levels fall in the brain leads to large number of the emergence of foul bad [17]. While, serotonin function increases in humans to strengthen the qualities of the positive behavior and the desired, whenever dropped the serotonin levels increased the emergence of aggressive behavior $[18,19]$. The serotonin receptors are located on the cell membrane of nerve cells and other cell types in animals, there are 14 know type of serotonin receptor and general varieties of serotonin receptor [20].

Serotonin receptor family is larger than any other family of G-protein coupled (GPCR) neurotransmitter receptors. These receptors are widely expressed throughout the brain and in many key structures responsible for cognition and basic brain functions. As one of the most ancient neurotransmitter systems, having appeared very early in

*Corresponding author: Rasha Hasan Jasim, Department of Chemistry, Faculty of Education for Girls, University of Kufa, Iraq, Tel: +9647265217601. E-mail: dr.rashahussainee@yahoo.com

Received July 20, 2017; Accepted August 16, 2017; Published August 18, 2017

Citation: Jasim RH, Matlab NS (2017) Serotonin as a Marker to the Response of Patients with Advanced Stages of Cancer during Treatment with Chemotherapy and Radiotherapy. Clin Med Biochem 3: 132. doi:10.4172/2471-2663.1000132

Copyright: @ $2017 \mathrm{Jasim} \mathrm{RH}$, et al. This is an open-access article distributed under the terms of the Creative Commons Attribution License, which permits unrestricted use, distribution, and reproduction in any medium, provided the original author and source are credited. 
evolution, its functions have been conserved and even expanded up through the various branches of the evolutionary tree [10].

\section{Materials and Methods}

During the period from the beginning of March 2016 to the end of September 2016; 358 individuals were enrolled in the present study and classified in three groups. The first group involved 201 patients with different malignant tumors, while the second group included 74 patients underwent benign tumors were used as a pathological controls, and the last group included 83 healthy individuals. The enrolled patients (malignant and benign tumors), were collected from several public and private hospitals in addition to centers in Al-Najaf Al-Ashraf governorate; involved: Al-Sadder Medical City, Al-Zahra Teaching Hospital, Al- Ameer Privet Hospital, Al-Ghadeer Hospital, Middle Euphrates Cancer Center, and Daily Specialized Najaf Clinic. Patients with malignant tumors were the basic group of the present study. Cancerous patients group were classified into six general subgroups (Breast, Lung, Brain, Bladder, Lymphoma, and Acute Lymphocytic Leukemia (ALL)) according to the cases that have been followed during treatment with chemotherapy or radiotherapy or together.

Five milliliters of venous blood samples were collected from the patients and healthy individuals, after fasting period more than eight hours. Samples were allowed to clot at lab temperature, centrifuged at 5000xg for 5 minutes. Sandwich-Enzyme-Linked Immune Sorbent Assay (Sandwich-ELISA) method was applied to evaluate of serotonin concentration.

\section{Results and Discussion}

Levels of serum Serotonin Concentration were measured in the three study groups; malignant and benign tumors' patients as well as healthy control individuals, at diagnosis and before treatment with chemotherapy or radiotherapy or the two types together. Table 1 shows a significant increase ( $p=0.011$, and 0.043 ) of serum serotonin levels in malignant tumors group when compared with those of benign tumors (as a pathological controls) group, and healthy individuals groups; respectively. No such results were shown when the two control (benign tumors and healthy individuals) groups were compared together (Table 1).

Exactly 192 cases of 201 malignant tumors patients showed high serotonin levels comparison to average serotonin levels at healthy individuals, so the sensitivity of serum serotonin in detection of cancerous tumors group was $95.52 \%$, while 65 cases of 74 patients with benign were recorded serotonin levels approximate or lower than average serotonin levels at healthy individuals, according to that the specificity of serum serotonin was $87.84 \%$.

The highest sensitivity of serotonin was recorded at brain cancer patients when $100 \%$ of cases showed high serotonin concentrations,

\begin{tabular}{|c|c|c|c|}
\hline $\begin{array}{c}\text { Groups } \\
\text { (n) }\end{array}$ & $\begin{array}{c}\text { Serotonin Concentration } \mathbf{( n g} / \mathbf{m l}) \\
\text { Mean } \pm \text { SD }\end{array}$ & Range & $\mathbf{p}$ \\
\hline $\begin{array}{c}\text { Malignant } \\
201\end{array}$ & $1.315 \pm 0.622$ & $\begin{array}{c}0.203- \\
2.721\end{array}$ & $\begin{array}{c}0.011 \\
\text { Malignant vs } \\
\text { Benign } \\
0.043\end{array}$ \\
\cline { 1 - 2 } $\begin{array}{c}\text { Benign } \\
74\end{array}$ & $0.856 \pm 0.594$ & $\begin{array}{c}0.152- \\
2.496\end{array}$ & $\begin{array}{c}\text { Malignant vs } \\
\text { Healthy } \\
0.858\end{array}$ \\
\cline { 1 - 2 } Healthy & $0.895 \pm 0.606$ & $0.031-$ & $\begin{array}{c}\text { Benign vs } \\
\text { Healthy }\end{array}$ \\
\hline
\end{tabular}

Table 1: Levels of serotonin concentration $(\mathrm{ng} / \mathrm{ml})$ in sera of tumoral patients and controls subjects (mean $\pm \mathrm{SD}$ ). followed by those of breast cancer (Sensitivity 97\%), while patients with bladder cancer recorded sensitivity of $93 \%$ in the detection malignant bladder tumors.

In general, serotonin has a participant role in several vital cell pathways when it is involved in the cell proliferation, apoptosis and platelet aggregation [14]. An elevation in the serotonin levels in the cancer cases may be explain through different hypothesis: During malignant transformation process, DNA translocation and amplification lead to an increased expression of oncogene proteins and loss of tumor suppressor gene protein [20], out results of these phenomena are alteration in the cellular proteins amounts so as nature, according to that an increase in the concentration of serotonin synthesis enzymes system may be involved as result for activation of genes expression [21]. Previous studies have been recorded abnormal activation in the production of serotonin synthesis cintermediates [10,12-14,21-23], so as enzymes, e.g., tryptophan hydroxylase and indolamine 2,3-dioxygenaee at prediction of cancers and directly arise at invasion stages $[11,24]$. Alterations in the expression of Serotonin Transporter (SERT) and Selective Serotonin Reuptake Inhibitors (SSRIs) may explained an observed increased in the serotonin concentration at malignant tumors patients. SERT is a glycoprotein belonging to the super-family of membrane bound $\mathrm{NaCl}$ dependent neurotransmitter transporters, characterized by 12 putative membrane spanning domains: it promotes serotonin clearance from the extracellular milieu and modifies the sensitization state of serotonin receptors within the nervous system or non-neural districts (gut, platelets, lymphomonocytes) [10,21,25-27]. An activation of SERT and/ or reduction of SSRIs as a results of mutations that caused malignancy occurred could be enhance serotonin production.

Increase of serotonin could be relate for activating of the serotonergic receptors sensitivity. Several studies highlighted on the probable role of alterations of the serotonin receptors action in enhancement of progressive loss of regulated cell proliferation, increased invasiveness, and increased metastatic potential of malignant cell [14,21,28-30]. Sleep disorder, anxiety, emotional disturbances, and appetite disorders are considered the most prominent features of the cancer development, from other side; many studies have been shown that these disorders are directly related to the alterations in levels of serotonin [12,31-33], so an elevation of serotonin concentration in the cancerous tumors groups may be reflex to the raise in the sleeping hours and decrease of food intake. Serotonin is stored in the intracellular vesicles and produced in response to many stimuli and factors [21], the present work suggests presence of overlap between the supposed factors to upgrade serotonin levels in the sera of malignant tumors patients.

Patients with malignant tumors undergoing to chemotherapy or radiotherapy in order to kill the greatest numbers of malignant cells and prevent recurrence of malignancy, on the other hand, patients with malignant tumors may receive chemotherapy for the purpose of increase the survival rate; especially those of the end invasive stages, when the size of tumor to the extent that prevents the vital member from performing them role even at the lowest level and then known as a gentle treatment. In order to follow serotonin concentrations at cancerous patients group, their levels were measured after treatment with the chemotherapy or radiotherapy, these doses were arranged from one to five. The average dose among total was used for the present comparison.

Student's t-test analysis of Serotonin concentration in the preand post- treatment with non-surgical strategies samples recorded significant decrease in the Serotonin concentration $(\mathrm{p}<0.05)$ as shown in Figure 1. 


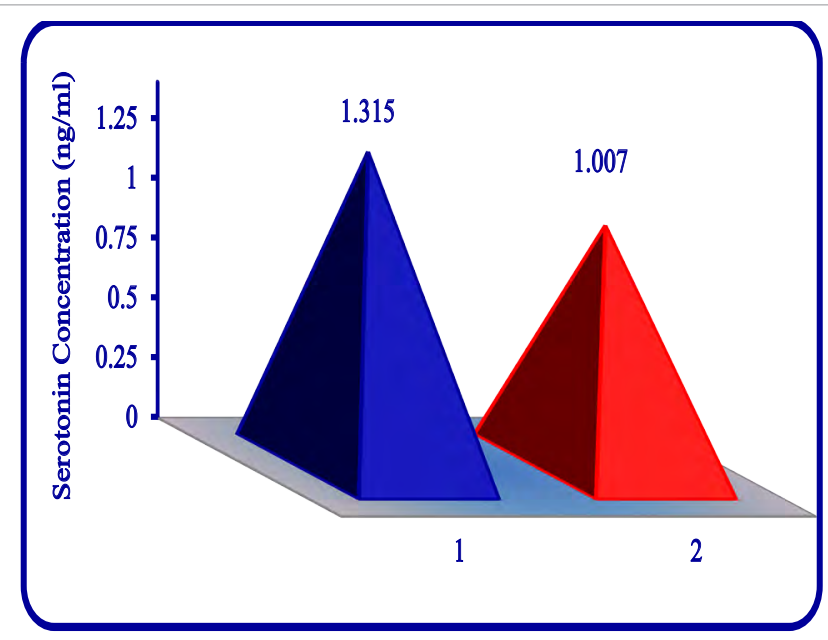

Figure 1: Comparison levels of serotonin in the sera samples of cancerous patients a detection firstly, then after treatment with chemotherapy (radiotherapy).

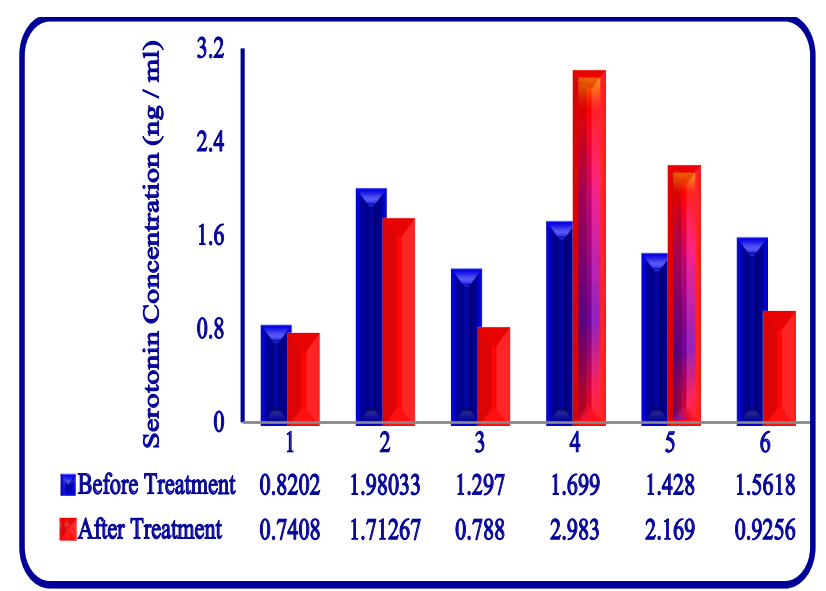

Figure 2: Serotonin concentration in the sera samples of patients with different malignant tumors at detection and after treatment with chemotherapy (radiotherapy).

Decreased of serotonin levels at cancerous patients group after treatment with chemotherapy or radiotherapy may explain as reflex to the decrease in the abnormal (cancerous) cells using toxic therapy. Consequently, the decrease in the serotonin concentration may decrease the vascularity of malignant cell then increase necrosis that finally leads to increase of cancer cell mortality.

Previously, several studies illustrated roles of different suggestive chemical compounds as chemotherapic agents [34,35]. In the 2002 team of researchers suggested 7-hydroxytryptophan as a highly specific chemotherapeutic compound against serotonin producing tumors that also interferes with the autocrine capabilities of serotonin synthesis, when they found that 7-hydroxytryptophan as analogue substrate specific tryptophan hydroxylase enzyme was capable of metabolizing in situ a harmless tryptophan analogue, to a potent toxin. The product of enzyme action (5,7-dihydroxytryptamine) which is a conversion blocked by the specific tryptophan hydroxylase inhibitor parachlorophenylalanine. Chosen of tryptophan hydroxylase for testing was intelligent idea, because it is the rate-limiting enzyme of serotonin biosynthesis, which is expressed highly in malignancy, as a target for the induction of cellular suicide by chemotherapy [36].
Weight gain is consider one of the side effect to the chemotherapy treatment, this increase in the body mass index may be give explanation to the increase in the serotonin levels at cancerous patients during the treatment period through multi mechanisms based to the intake of food richly proteins, $[37,38]$ alternative metabolic pathways of tryptophan [12], changes in the transport serotonin proteins, [39] reduction in the ability of different enzymes involved in the serotonin synthesis pathway, and serotonin receptors $[31,40,41]$. For monitoring the changes in the serum levels of serotonin with details; the cancer cases with the largest number of samples were selected, here the selected cases of the malignant patients group were subdivided into six different types (Breast, Lung, Brain, Bladder, Lymphoma, and Acute Lymphocytic Leukemia (ALL)) were enrolled in the present section. Levels of serotonin were evaluated in sera samples of selected cancers' cases at pre- and post- at least two dosages of chemotherapy (or radiotherapy) treatment.

Highest serotonin concentrations were recorded at group of lung cancers, followed by bladder cancers, while the lowest serotonin concentrations were recorded at group of patients with malignant breast tumors. After treatment, serotonin levels were decreased in the total malignant tumors group as will show in the Figure 1, only bladder cancer and lymphoma groups showed significant increase in the serotonin levels comparison to their levels at diagnosis, as show in Figure 2.

Levels of serotonin in bladder cancer and lymphoma samples seem to need extensive study separately.

\section{References}

1. Bray A, Johnson H, Raff L, Walter R (2015) Cellular Communities: Tissues, Stem Cells and Cancer. In: Essential cell biology. 3rd edn. Garland Science, United States of America, pp: 689-730.

2. Hejmadi $M(2010)$ Introduction to cancer biology. 2nd edn. Maersk, pp: 1-48

3. Malikic S (2014) Clonality Inference in Multiple tumor Samples Using Phylogeny. Thesis, Faculty of Applied Sciences, Simon Fraser University, Canada.

4. Hartwell L (2004) Cell Biology and Cancer.

5. Nigrini S, Gorgoulis VC, Hala TD (2010) Genomic instability an evolving hall mark of cancer. Mol Cell 11: 220-228.

6. Harvey RA, Ferrier DR (2011) Lippincott's Illustrated Reviews. Biochemistry 5th edn. China.

7. Seyfried TN, Shelton LM (2010) Cancer as a metabolic disease. Nutrition Metabolism 7: 1-22.

8. Hanahan D, Weinberg RA (2011) Hallmarks of Cancer: The Next Generation Cell 144: 646-674.

9. Sitarz R, Bzoma MK, Gliwa EJK, Kurylcio A, Mielko J, et al. (2012) Healthrelated behaviors among the lubin province population. Zdr Publ 122: 227-232.

10. Nichols DE, Nichols CD (2008) Serotonin Receptors. Chem Rev 108: 16141641.

11. Pytliak M, Vargova V, Mechirova V, Felasoci M (2011) Serotonin Receptors From Molecular Biology to Clinical Applications. Physiol Res 60: 15-25.

12. Chojnacki C, Walecka KE, Stepien A, Pawlowicz M, Wachowska KP, et al. (2013) Serum and ascitic fluid serotonin levels and 5-hydroxyindoleacetic acid urine excretion in the liver of cirrhotic patients with encephalopathy. Advances in Medical Sciences 58: 251-256.

13. Sarrouilhe D, Clarhaut J, Defamie N, Mesnil M (2015) Serotonin and Cancer: What is the Link?. Current Molecular Medicine 15: 62-77.

14. Elshayeb El, Korani MAR, Elmaidany NF, Helwa MA, Abd-Elatty EA (2016) Serum Serotonin as a Novel Marker for Hepatocellular Carcinoma. Adv Res Gastroentero Hepatol 1: 1-7.

15. Berger M, Gray JA, Roth BL (2009) The expanded biology of serotonin. Annu Rev Med 60: 355-366.

16. Bertrand PP (2004) Real-time detection of serotonin release from 
Citation: Jasim RH, Matlab NS (2017) Serotonin as a Marker to the Response of Patients with Advanced Stages of Cancer during Treatment with Chemotherapy and Radiotherapy. Clin Med Biochem 3: 132. doi:10.4172/2471-2663.1000132

enterochromaffin cells of the guinea-pig ileum. 5: 511-514.

17. Crockett MJ, Schoute AA, Herrmann B, Lieberman M, Muller U, et al. (2013) Serotonin Modulates Striatal Responses to Fairness and Retaliation in Humans. The Journal of Neuroscience 33: 3505-3513.

18. Crockett MJ, Clark L, Tabibnia G, Lieberman MD, Robbins TW (2008) Serotonin modulates behavioral reactions to unfairness. Science 320: 1739.

19. Crockett MJ, Clark L, Hauser MD, Robbins TW (2010) Serotonin selectively influences moral judgment and behavior through effects on harm aversion. Proc Natl Acad Sci USA 107: 17433-17438.

20. American Cancer Society (2016) Cancer Facts Figures, American Cancer Society Inc., Atlanta. 500816.

21. Frobe A, Cicin-Saini L, Jones G, Soldic Z, Lukac J, et al. (2014) Plasma Free Serotonin as a Marker for Early Detection of Breast Cancer Recurrence. Anticancer Research 34: 1167-1170.

22. Joy T, Walsh G, Tokmakejian S, Van V, Uum SH (2008) Increase of Urinary 5 -Hydroxyindoleacetic Acid Excretion but not Serum Chromogranin a following Over-the-Counter 5-Hydroxytryptophan Intake. Can J Gastroenterol 22: 49-53.

23. Greco AV, Mingrone G, Favuzzi A, Bertuzzi A, Gandolfi A, et al. (2000) Subclinical Hepatic Encephalopathy: Role of Tryptophan Binding to Albumin and the Competition with Indole-3-Acetic Acid. J Investig Med 48: 274-280.

24. Juhász C, Nahleh Z, Zitron I, Chugani DC, Janabi MZ, et al. (2012) Tryptophan Metabolism in Breast Cancers: Molecular Imaging and Immunohistochemistry Studies. Nucl Med Biol 39: 926-932.

25. Giannaccini G, Betti L, Palgo L, Marsili A (2013) The Expression of Platele Serotonin Transporter (SERT) in Human Obesity. BMC Neuroscience 14: 1-8.

26. O'Mahony SM, Clarke G, Borre YE, Dinan TG, Cryan JF (2015) Serotonin Tryptophan Metabolism and the Brain-Gut-Microbiome Axis. Behav Brain Res 277: 32-48.

27. Ruddell RG, Oakley F, Hussain Z, Yeung I, Bryan-Lluka LJ (2006) A role for Serotonin (5-HT) in Hepatic Stellate Cell Function and Liver Fibrosis. Am J Pathol 169: 861-876.

28. Frampton GA, Huang L, Ramirez J, Mohamad A, DeMorrow S (2010) Biogenic amines serotonin and dopamine regulate cholangiocyte hyperplastic and neoplastic growth. World J Gastrointest Pathophysiol 1: 63-68.

29. Pai VP, Marshall AM, Hernandez LL, Buckley AR, Horseman ND (2009) Altered serotonin physiology in Human Breast Cancers Favors Paradoxical
Growth and Cell Survival. Breast Cancer Res 11: 81

30. Gautam J, Banskota S, Regmi SC, Ahn S, Jeon YH, et al. (2016) Tryptophan Hydroxylase 1 and 5-HT7 Receptor Preferentially Expressed in Triple-Negative Breast Cancer Promote Cancer Progression Through Autocrine Serotonin Signaling. Mol Cancer 15: 75.

31. Lefta AA (2017) Biochemical Evaluation of the Levels of Oxytocin, Serotonin and Some Oxidative Stress Parameters in Sera of Patients with Morbid Obesity. Theses. Department of Chemistry, The Faculty of Education for Girls, University of Kufa, Iraq.

32. Kohyama J (2012) Sleep, Serotonin and Suicide. Journal of Behavioral and Brain Science 2: 471-478.

33. Lima HRC, Cavalcante-Lima HR, Cedraz-Mercez PL, Costa-E-Sousa RH Olivares EL, et al. (2004) Brain Serotonin Depletion Enhances the Sodium Appetite induced by Sodium Depletion or Beta-Adrenergic Stimulation. Anais da Academia Brasileira de Ciências 76: 85-92.

34. Zitvogel L, Apetoh L, Ghiringhelli F, Kroemer G (2008) Immunological aspects of Cancer Chemotherapy. Nature Publishing Group 8: 59-73.

35. Lakshmi PM, Bhanu PK, Kotakadi VS, Joshna P (2015) Herbal and medicina plants molecules towards treatment of cancer: A mini review. American Journal of Ethnomedicine 2: 136-142.

36. Wither DJ, Peter JU, Bader M (2002) 7-Hydroxytryptophan, a Novel, Specific Cytotoxic Agent for Carcinoids and other Serotonin - Producing Tumors. Cancer 94: 3135-3140.

37. Rohini K, Bhat S, Srikumar PS, Saxena J, Mahesh KA (2013) Body Weight Gain in Pulmonary Tuberculosis during Chemotherapy. International Journal of Collaborative Research on Internal Medicine Public Health 5: 247-254.

38. Atalay C, Kucuk Al (2015) The Impact of Weight Gain during Adjuvan Chemotherapy on Survival in Breast Cancer. Ulus Cerrahiderg 31: 124-127.

39. Timothy C, Birdsall ND (1998) 5-Hydroxytryptophan: A Clinically-Effective Serotonin Precursor. Altern Med Rev 3: 271-280.

40. Watanabl H, Nakan T, Saito R, Akasaka D (2016) Serotonin improves High Fat Diet induced Obesity in Mice. PLoS ONE 10: 1-14.

41. Polvani S, Tarocchi M, Tempesti S, Bencini L, Galli A (2016) Peroxisome Proliferator Activated Receptors at the Crossroad of Obesity, Diabetes, and Pancreatic Cancer. World J Gastroenterol 22: 2441-2459. 